\title{
Evidence of a limited contribution of feto-maternal interactions to trophoblast differentiation along the invasive pathway
}

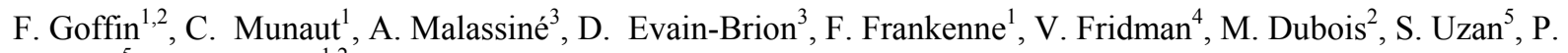 \\ Merviel $^{5}$, J-M. Foidart ${ }^{1,2}$ \\ ${ }^{1}$ Laboratory of Tumor and Developmental Biology, nstitute of Pathology, Liège, Belgium, ${ }^{2}$ Department of Obstetrics and Gynecology, \\ Hôpital of la Citadelle, Liège, Belgium, ${ }^{3}$ Inserm U4 27, Institute of Pharmacy, Paris, France, ${ }^{4}$ Department of Pathology, nstitute of \\ Pathology, Liège, Belgium, ${ }^{5}$ Department of Obstetrics and Gynecology, Hôpital Tenon, Paris, France
}

\begin{abstract}
Trophoblast differentiation is a key event in human placental development. During extravillous trophoblast (EVT) differentiation, stem cells from the anchoring villi detach from their basement membrane and proliferate to form aggregates called trophoblast cell columns (TCCs). They subsequently invade the decidua and differentiate into interstitial and endovascular trophoblasts. The influence of the decidua on EVT differentiation is controversial. We therefore compared the pattern of trophoblast differentiation marker expression in viable intrauterine and tubal pregnancies, as decidual cell markers (prolactin [PRL] and insulin-like growth factor binding Protein-1 [IGFBP1]) were only expressed in endometrial implantation sites. Extravillous trophoblast differentiation in anchoring villi from uterine and ectopic pregnancies exhibited a comparable phenotypical switch: $\alpha 6$ integrin subunit, E-cadherin, EGF receptor, Ki 67 and connexin 40 were localized in the proximal part of the TCC, while $\alpha 5 \beta 1$ and $\alpha$ l integrins, c-erb B2, hPL and HLA-G were expressed by invasive cytotrophoblasts. The cyclin-dependent kinase inhibitors p16 and p57 were mainly detected in invasive cytotrophoblasts some distance from the columns. However, the TCC was markedly longer in tubal pregnancy than in intrauterine pregnancy. These findings suggest that the decidua is not necessary to trigger EVT invasion, but that it is likely to limit the extent of the TCC and to accelerate the onset of EVT migration.
\end{abstract}

Key words: deciduas; fallopian tube; implantation; trophoblast

\section{INTRODUCTION}

Successful human placentation necessitates a series of events involving cellular and molecular interactions between specialized fetal and maternal cells. Two major morphologically and functionally distinct cytotrophoblast populations can be identified in human placenta. Villous cytotrophoblasts are polarized immotile cells that fuse to form the overlying syncytium in direct contact with maternal blood. Extravillous cytotrophoblast (EVT) cells derive from cytotrophoblasts (CTBs) that rest on a basement membrane surrounding the tips of anchoring villi. Extravillous trophoblasts proliferate and differentiate as they leave their basement membrane and form cellular aggregates (Le. trophoblast cell columns: TCC). When they become invasive, individual cytotrophoblasts invade the endometrium and, eventually, its arterial system (1). The human placenta is characterized by extensive invasion of EVTs into the maternal uterus, allowing trophoblasts to be in direct contact with maternal blood (hemochorial placentation) $(2,3)$. The EVTs switch from a proliferative to an invasive phenotype is governed by the sequentially regulated expression of a pleiad of genes (4-9). Extravillous trophoblast invasion proceeds mechanisms similar to those used by malignant cells to invade host tissues $(10,11)$.

In normal pregnancy, EVTs are in close contact with maternal decidual cells derived from the differentiation of endometrial stromal cells under the influence of progesterone. Decidualization is a feature unique to those species that exhibit invasive hemochorial placentation (12). The extent of decidualization in mammals is closely related to the degree of trophoblast invasiveness into the uterus (13). The most pronounced trophoblast invasion and decidual changes occur in humans. Decidualization is characterized (1) by the presence of swollen endometrial stromal cells $(14)$, limited by a basement-membrane-like material $(15,16)(2)$, by the acquisition of specific endocrine activities, and (3) by the presence of numerous immune cells (17).

Decidualization is generally regarded as an endometrial barrier that limits trophoblast invasion and protects the uterus from irreversible damage as a result of excessive hemochorial placentation (18-20). Others consider that 
the decidua promotes trophoblast migration $(12,21)$. Several in vitro studies have attempted to evaluate the potential role of isolated decidual components in trophoblast activities (19, 21-23). However, in vitro experimental settings fail to mimic the complex in vivo situation. Ectopic pregnancy occurs in tissues that are classically considered to exhibit impaired or absent decidualization (2, 24-26).

In this study, we first compared the expression of specific markers of decidualization (prolactin and IGFBP-1) in intrauterine and tubal pregnancies. We then examined the distribution of several markers of EVT proliferation, invasion and differentiation in normal and ectopic pregnancies in order to determine the possible contribution of the decidua to their expression by the EVTs. Despite the absence of decidualization markers in tubal pregnancy, the patterns of cadherins, integrins, connexins, epidermal growth factor receptor (EGF-R), c-erb-B2, human placental lactogen (hPL), human leukocyte antigen-G (HLA-G) and cyclin-dependant kinase inhibitors (p16, p57) were identical to those of intrauterine pregnancies. However, the length of the TCC was considerably lower in intrauterine pregnancy.

These data indicate that the acquisition of the EVT invasive phenotype occurs in the absence of decidua. They are however, consistent with a role of maternal decidual in limiting the size of the TCC and promoting the dissociation of cell aggregates and thereby the spreading of individual EVTs.

\section{MATERIALS AND METHODS}

\section{Tissue sources}

Ectopic implantation sites were collected during 60 laparoscopic salpingectomies performed for tubal pregnancy. Age-matched first-trimester placentas were obtained by aspiration during legal elective abortion for non-medical reasons. In addition, full-thickness implantation sites in one hysterectomy specimen (10 weeks) were also studied. The protocol was approved by our local university Ethics Committee. The gestational age and viability of tubal pregnancies were determined by vaginal ultrasonography immediately before surgery (measure of the crown-rump length and fetal heart activity) and were also calculated from the time of embryo transfer during IVF procedures (Table 1). Specimens were frozen in liquid nitrogen and stored at $-70^{\circ} \mathrm{C}$ until use, or fixed in neutral buffered $10 \%$ formalin before embedding in paraffin.

Among the 60 pregnant tubes collected by salpingectomy, only six fulfilled the criteria of evolutive pregnancy. In these latter pregnancies, anchoring villi were observed with no evidence of necrosis, marked inflammatory infiltration or hemorrhage. In aborted ectopic pregnancies, typical anchoring villi could not be detected in all cases.

The length of the trophoblast cell column was compared at tubal and intrauterine implantation sites. Using Olympus Micro-image 3.0.1 software (Omnilabo, Aartselaar, Belgium), we measured the distance separating the fetal mesenchyme core from the mesenchyme of the maternal decidua (for example, see $\rightarrow$ in Figs 1B3 and B4). Tubal pregnancies $(n=6)$ were compared with placental tissue obtained either by aspiration $(n=10)$ or by hysterectomy (one gravid specimen at 10 weeks of pregnancy). One hundred columns attached to the maternal site were measured. Statistical analysis was performed using the Mann-Whitney test. P-values less than 0.05 were considered to denote significance.

\section{Morphological studies}

\section{Antibodies}

The sources of the first-step antibodies are indicated in Table 2. Rhodamine-labeled rabbit antimouse and swine antirabbit antibodies were purchased from Dako (Glostrup, Denmark) (Table 2).

\section{Immunohistochemistry on frozen specimens}

Frozen sections (6 $\mu \mathrm{m}$ thick) were prepared using a Leica CM3050S cryostat and collected on 3aminopropyltriethoxysilan (Sigma, St Louis, MO) -coated glass microscope slides (Labonord, Belgium).

Sections were fixed in acetone $\left(-20^{\circ} \mathrm{C}\right)$ for $10 \mathrm{~min}$ (for integrins $\alpha 1, \mathrm{x} 5 \beta 1$ and $\alpha 6$ and E-cadherin staining), in $4 \%$ paraformaldehyde for 20min (for HLA-G, Ki-67, cyclin-dependent kinase inhibitors pl6 and p57, EGF-R and cerb B2 staining) or in methanol at $-20^{\circ} \mathrm{C}$ for $10 \mathrm{~min}$ (for connexin 32,40 and 43 staining). 
After fixation, slides were washed three times in phosphate-buffered saline (PBS) for 5min. Non-specific binding sites were blocked by placing the slides in $10 \%$ bovine serum albumin (BSA, Sigma) for 30min. For EGF-R, c-erb B2 and connexins 32, 40 and 43, the blocking solution consisted of 2\% BSA and 1\% Triton X100 in PBS. After three washes in PBS, the slides were incubated for $1 \mathrm{~h}$ with an appropriate dilution of the primary antibody (in 1\% BSA) or overnight at $4^{\circ} \mathrm{C}$ (for connexins 32, 40 and 43 ). After five further washes, the second antibody conjugated to rhodamine was applied for $30 \mathrm{~min}$ and the slides were washed three times in PBS for 5 min. After incubation with the different antibodies, nuclei were labeled with 4',6-diamidino-2-phenylindole (DAPI, $1 \mu \mathrm{gmL}^{-1}$ ) for $20 \mathrm{~min}$, washed for $5 \mathrm{~min}$ in PBS and mounted with Aquapolymount anti-fading solution (Agar, UK). All incubations and washes were performed at room temperature. Appropriate controls were prepared with the same procedure but omitting the primary antibody or replacing the primary antibody with a non-specific IgG antibody at the same concentration. The controls were always negative. Samples were examined with an Olympus IX50 fluorescence microscope equipped with appropriate filters (Omnilabo, Aartselaar, Belgium).

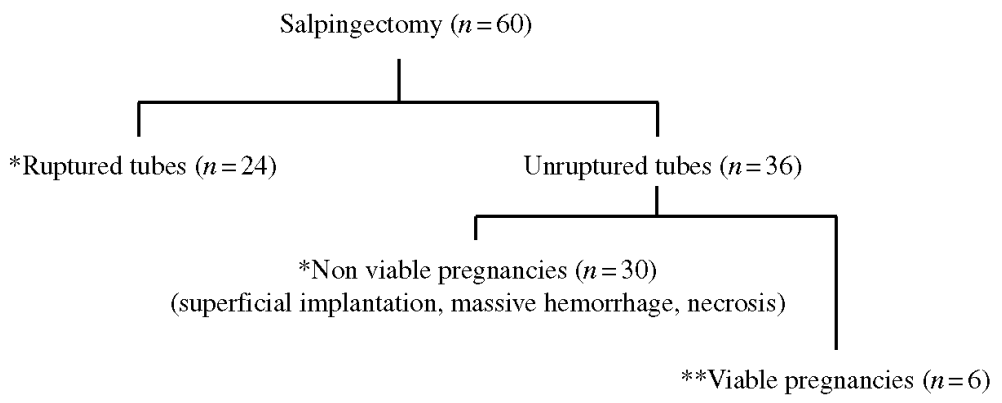

Table 1: Salpingectomy

\begin{tabular}{ccccc}
\hline No. & Implantation site & Circumstances of diagnosis & Gestational age (weeks) & HCG (IU mL $\left.\mathbf{~}^{\mathbf{- 1}}\right)$ \\
\hline 1 & Ampulla & Asymptomatic & 11 & 58,000 \\
2 & Ampulla & Abdominal pain & 8 & 9,640 \\
3 & Ampulla & Abdominal pain & 8 & 13,100 \\
4 & Ampulla & IVF follow up & 7 & 8,600 \\
5 & Ampulla & IVF follow up & 6 & 7,000 \\
6 & Ampulla & IVF follow up & 6 & 7,600 \\
\hline
\end{tabular}

immunohistochemistry. $n=60$.

\section{Immunohistochemical staining of IGFBP-1, hPL and cytokeratin 7}

Paraffin sections ( $6 \mu \mathrm{m}$ thick) were de-waxed in xylene and rehydrated in PBS. Endogenous peroxidase activity was quenched by incubation with 3\% hydrogen peroxide in PBS for $10 \mathrm{~min}$. Non-specific antibody binding was blocked by incubation for $30 \mathrm{~min}$ in blocking reagent containing 10\% BSA in PBS. The primary antibodies

(Table 2) were diluted in $1 \%$ BSA and incubated with the sections for $1 \mathrm{~h}$ at room temperature. After washing, a peroxidase-conjugated swine anti-rabbit or rabbit antimouse antibody was applied for 30 min at room temperature. The slides were then incubated with a solution of diaminobenzidine and $0.03 \%$ hydrogen peroxide, then washed in running tap-water and counterstained with hematoxylin. Sections were mounted in Eukitt (Labonord, Belgium), examined and photographed under an Olympus IX50 microscope. Controls were prepared as described above.

\section{Prolactin RT-PCR}

Tubal implantation sites $(n=6)$ containing floating and anchoring villi and the tubal wall were identified histologically on hematoxylin-stained frozen slides. Ten $10-\mu \mathrm{m}$ thick frozen sections were prepared in a Leica CM3050S cryostat and placed in lysis buffer (Rneasy Mini Kit, Qiagen, GmbH, Hilden, Germany) for RNA extraction. Using the same procedure, RNA was also extracted from normal implantation sites of five 
intrauterine first-trimester pregnancies and from six uterine decidua samples from the patients who had tubal pregnancies $(n=6)$. Prolactin gene expression (PRL) was also examined in endometrial tissue from the proliferative phase (negative controls, $n=10$ ) and the late luteal phase (positive controls, $n=10$ ).

For RNA purification, samples were lyzed, then homogenized and processed as recommended by the manufacturer.

Fig. 1: (A) First-trimester uterine and fallopian tube pregnancies. (B) First-trimester anchoring villous with extravillous trophoblasts (EVTS) forming the cell column at the fetal-maternal interface in uterine pregnancy (UP) and viable tubal pregnancy (TP) (B1 and B2: hematoxylin and eosin staining). Scale bar $=100 \mu \mathrm{m}$. Immunoperoxidase labeling with anticytokeratin 7 antibody stained all trophoblast populations, including the villous trophoblast and EVTs (B3 and B4). Long $\rightarrow$ denote the direction of EVT migration. VM = villous mesenchyme; EVT = extravillous trophoblast of the cell column. Scale bar $=100 \mu \mathrm{m}$.
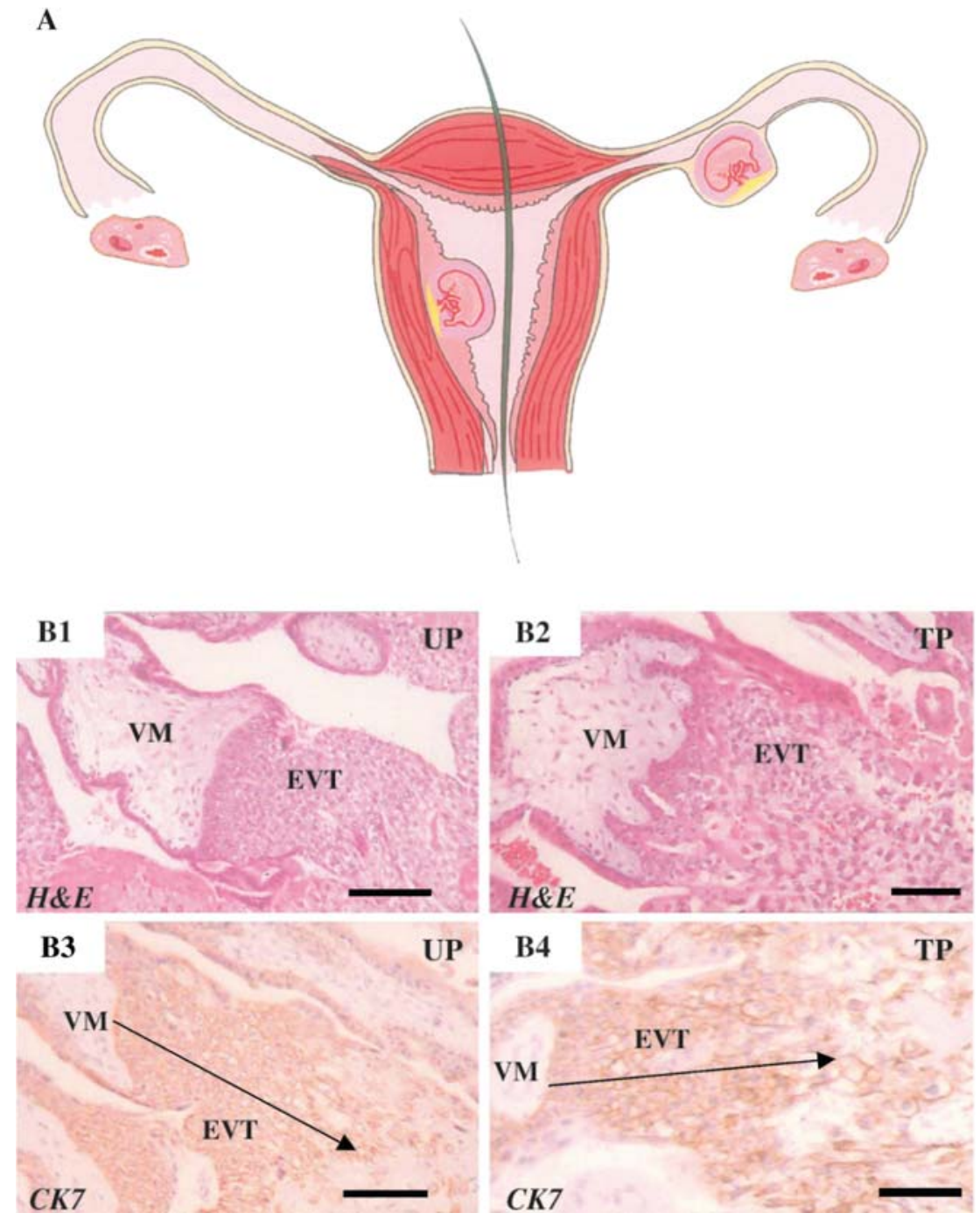

Prolactin gene expression mRNA and 28S rRNA were measured in aliquots of total RNA (10 ng) by RT-PCR. RT-PCR was carried out using the GeneAmp Thermostable rTth reverse transcriptase RNA PCR kit (Perkin Elmer, Branchburg NJ) and two pairs of primers (Eurogentec, Liège, Belgium). The sequence of the sense primer for PRL was $\delta^{\prime}$-GGTGACCCTTCGAGACCTGTT-S' and that of the antisense primer 5'-GGAAGAAGTGTGGCAGCTGTT-3'. The sequence of the sense primer for 28S rRNA was 5'-GTTCACCCAC-TAATAGGGAACGTGA-3', and that of the antisense primer 5'-GATTCTGACTTAGAGGCGTTCAGT-3'. Reverse transcription was performed at $70^{\circ} \mathrm{C}$ for $15 \mathrm{~min}$, followed 
by 2 min of incubation at $95^{\circ} \mathrm{C}$ to denature the RNA-DNA heteroduplexes. Amplification started at $94^{\circ} \mathrm{C}$ for 15 $\mathrm{s}, 30 \mathrm{~s}$ at $60^{\circ}$ and $15 \mathrm{~s}$ at $72^{\circ} \mathrm{C}$ for 35 cycles for PRL (for $28 \mathrm{~S}$ rRNA the annealing temperature was $20 \mathrm{~s}$ at $68^{\circ} \mathrm{C}$ and extension was $10 \mathrm{~s}$ at $72^{\circ} \mathrm{C}$ for 19 cycles) and terminated by 2 min at $72^{\circ} \mathrm{C}$ The RT-PCR products were resolved on 10\% acrylamide gels and analyzed using a Fluor-S Multilmager (Bio-Rad, Hercules, CA) after staining with Gelstar dye (FMC Bioproducts, Rockland, ME). The expected sizes of the PRL mRNA and 28S rRNA were $150 \mathrm{bp}$ and $212 \mathrm{bp}$, respectively. RT-PCR was performed three times on each sample.

Table 2: Antibodies used for immunohistochemistry

\begin{tabular}{|c|c|c|c|c|c|}
\hline \multirow{2}{*}{$\frac{\text { Antigens }}{\text { Cytokeratin } 07}$} & \multirow{2}{*}{$\frac{\text { mAbs }}{\text { OV-TL 12/30 }}$} & \multicolumn{2}{|c|}{ Species Isotype } & \multirow{2}{*}{$\begin{array}{l}\text { Dilution } \\
1: 200\end{array}$} & \multirow{2}{*}{$\begin{array}{l}\text { Suppliers } \\
\text { Dako }\end{array}$} \\
\hline & & Mouse & $\operatorname{IgG1}$ & & \\
\hline Vimentin & V9 & Mouse & IgG1 & $1 / 200$ & Dako \\
\hline hPL & A0137 & Rabbit & - & $1: 300$ & Dako \\
\hline hPRL & - & Rabbit & - & $1: 200$ & Dr Parlow-NIDDK \\
\hline hPRL & A0569 & Rabbit & - & 1.200 & Dako \\
\hline hPRL & NCL-PRO & Mouse & $\lg \mathrm{G} 3$ & $1: 200$ & NovoCastra \\
\hline IGFBP-1 & 6303 & Mouse & - & $1: 100$ & Medix Biochemica \\
\hline$\alpha 6$ subunit & $\mathrm{SP} 2 / 0$ & Mouse & $\operatorname{lgG} 2 b$ & $1: 50$ & Immunotech (Cappel) \\
\hline$\alpha 5 \beta 1$ & P1D6 & Mouse & $\lg \mathrm{g} 3$ & $1: 50$ & Dako \\
\hline subunit & $\mathrm{TS} 2 / 7$ & Mouse & $\operatorname{IgG} 1$ & $1: 50$ & T Cell Diagnostic \\
\hline E-Cadherin & SHE 78-7 & Mouse & $\lg \mathrm{g} 2$ & $1 / 100$ & Zymed \\
\hline EGF-R & - & Mouse & $\operatorname{IgG1}$ & $1: 100$ & Genzyme \\
\hline c-erbB 2 & 9G6 & Mouse & $\operatorname{IgG} 1$ & $1: 10$ & Calbiocem \\
\hline Connexin 40 & - & Rabbit & - & $1: 50$ & Dr D. Gros, Marseille \\
\hline Connexin 32 & - & Mouse & IgG1 & $1: 100$ & Zymed \\
\hline Connexin 43 & - & Mouse & IgG1 & $1: 100$ & Transduction Laboratories \\
\hline p16 & P16 (F-12) & Mouse & IgG1 & $1 / 150$ & Santa Cruz Biotechnology \\
\hline $\mathrm{p} 57$ & & Mouse & IgG1 & $1 / 150$ & Santa Cruz Biotechnology \\
\hline $\mathrm{Ki}-67$ & MIB-1 & Mouse & $\operatorname{IgG} 1$ & $1: 50$ & Immunotech \\
\hline HLA-G & W6/32 & Mouse & $\lg \mathrm{g} 2 \mathrm{a}$ & $1 / 100$ & Leinco Technologies \\
\hline
\end{tabular}

\section{RESULTS}

Most ectopic pregnancies occur in the ampulla. Figure 1A schematically illustrates uterine and fallopian implantation sites. Figure 1B shows the typical structure of an anchoring villous in utero (Fig. 1B1) and in a fallopian tube (Fig. 1B2). The fetal mesenchymal core is surrounded by a layer of cytotrophoblast covered by the syncytium, and the EVTs form cellular aggregates called TCCs. Using an anticytokeratin 7 antibody, which stains all trophoblast populations, trophoblastic cells were distinguished from non-epithelial maternal cells of the uterine decidua (Fig. 1B3) or the fallopian tube (Fig. 1B4). In pregnant tubes, trophoblast cells that had migrated into the fallopian tube tended to have the morphology of cohesive rounded cells (Figs 1B2,4 and 7B, D, F).

\section{Absence of decidual cells in tubal implantation sites}

To detect decidual cells in tubal pregnancies, we studied PRL expression in tubal implantation sites by means of RT-PCR. As shown in Fig. 2, PRL transcripts were observed in the secretory endometrium in normal pregnancies, and in the intrauterine decidua in tubal pregnancies. In contrast, no expression was detected in the tubal implantation sites or proliferative endometrium. As previously reported $(27,28)$, significant crossreactivity of commercial anti-PRL antibodies with $\mathrm{hPL}$ precluded their use for immunohistochemical studies of placental tissue. IGFBP-1, another marker of decidual cells, was not expressed in the tubal implantation sites (Fig. 3C), but was clearly expressed in the intrauterine decidua of both normal (Fig. 3A) and tubal pregnancies (Fig. 3B). In the serial sections, vimentin staining (Fig. 3D) identified maternal mesenchymal cells, and cytokeratin or hPL staining confirmed the presence of invasive EVTs in tubal implantation sites (Fig. 3E and F). 


\section{Pattern of trophoblast differentiation markers in uterine and tubal pregnancies (Table 3)}

\section{Integrin expression pattern}

Figure 4A shows the intense and polarized localization of the $\alpha 6$ integrin subunit at the basal pole of villous trophoblasts. The $\alpha 6$ staining was no longer polarized and gradually weakened as trophoblast distance from the anchoring site increased, disappearing in the deepest layers. No differences in $\alpha 6$ integrin subunit distribution were found between the uterine and tubal pregnancies.

Uterine and tubal implantation sites displayed a similar $\alpha 5 \beta 1$ integrin distribution, which was exactly opposite to the $\alpha 6$ integrin subunit distribution, with positive staining of distal trophoblasts only (Fig. 4B).

Positive staining for the $\alpha 1$ integrin subunit was observed in the mesenchymal core of the fetal villi in the tubal and intrauterine pregnancies (Fig.4C). At the implantation site of the intrauterine and ectopic pregnancies, the $\alpha$ l integrin subunit was absent from the proximal part of the cell column. This $\alpha$ integrin subunit was again expressed by invasive trophoblast cells in the distal part of the column (Fig.4C). The $\alpha 1$-expressing EVTs in distal columns were distinguished from maternal cells by cytokeratin 7 staining of serial sections (data not shown). This pattern is identical to that observed in intrauterine pregnancies, as previously reported $(8,29)$.

Fig. 2: Analysis of prolactin (PRL) and 28S mRNA RT-PCR products amplified from proliferative endometrium $(P E, m=10)$, secretory endometrium (SE, $m=10)$ and uterine decidua from patients with tubal pregnancy (decidua, $m=6)$, uterine pregnancy (UP, $m=5$ ) and tubal pregnancy (TP, $m=6)$. (A) Representative electrophoresis of prolactin (PRL) and 28S RT-PCR products showing the absence of PRL transcripts in proliferative endometrium and tubal pregnancy (TP). (B) PRL mRNA levels estimated from the density of the electrophoresis band. Values are mean \pm SEM and represent the PRL to $28 \mathrm{~S}$ band density ratio. Prolactin transcripts, used as a marker of decidualization, are restricted to late secretory endometrium and to the endometrium of patients with tubal pregnancy (decidua) or intrauterine pregnancy (UP).

A

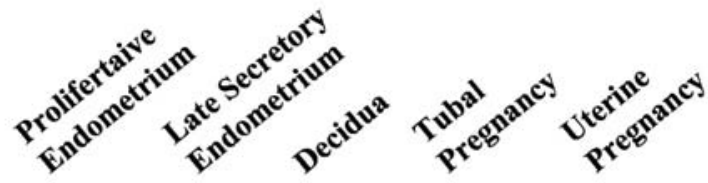

\section{PRL}

PRL / 28 S

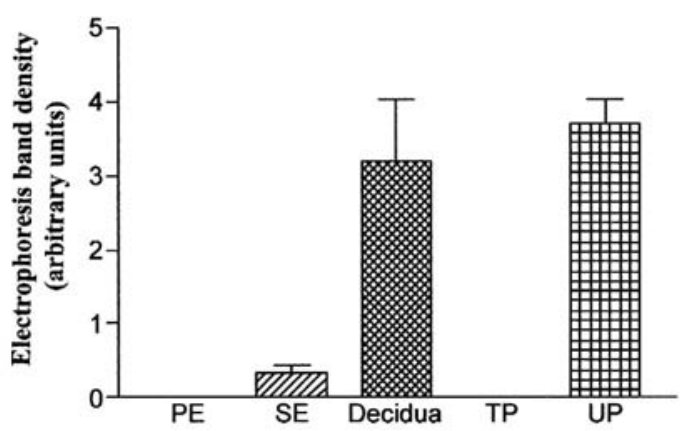


Fig. 3: Immunoperoxidase staining for IGFBP-1, used as a marker of decidual differentiation.

(A) IGFBP-1 detection in decidualized endometrial stromal cells $(\rightarrow$ ) of an intrauterine pregnancy (UP).

(B) Endometrial stromal cells $(\rightarrow)$ in a representative case of tubal pregnancy (TP) also express IGFBP-1. Staining for IGFBP-1 (C), vimentin (D), CK7 (E) and hPL (F) was performed on serial sections from a representative tubal implantation site. Arrowheads show invasive extravillous trophoblasts (EVTs) reacting with anti-CK7 (E) and antihPL (F) antibodies. Vimentin-positive cells correspond to stromal cells and vascular cells. Scale bar $=50 \mu \mathrm{m}$.
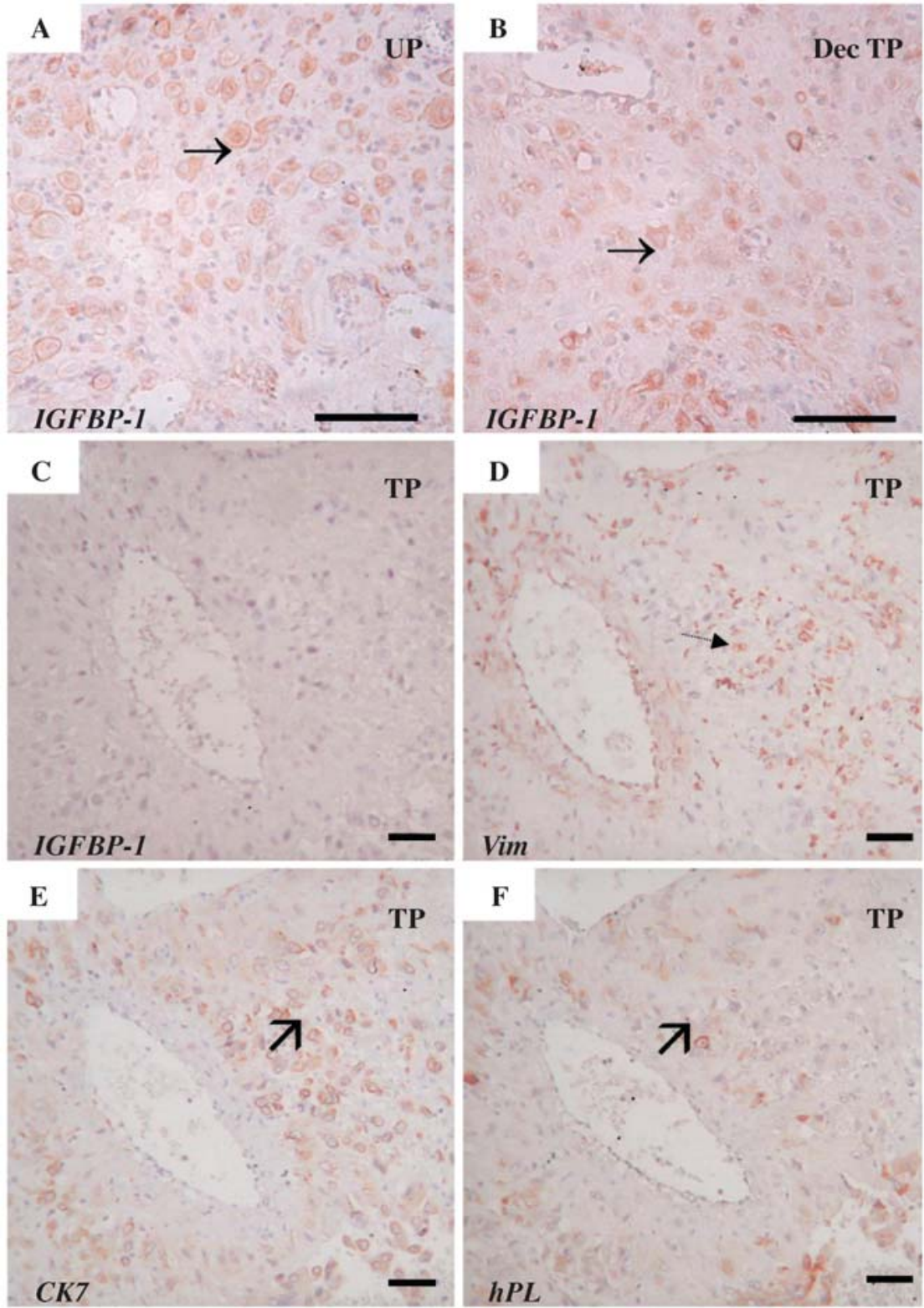

\section{E-cadherin and connexins}

In both uterine and tubal implantation sites, E-cadherin was detected in villous trophoblasts and in proximal EVTs, but was minimally expressed in distal EVTs (Fig. 5A).

In both uterine and tubal implantation sites, $\mathrm{Cx}-40$ staining was prominent in the proximal cell column, where cells were still in close contact with each other (Fig. 5B). Cx-40 was absent from distal and dispersed EVTs. Cx43 was restricted to the villous trophoblasts of endometrial and tubal pregnancies. The pattern of expression was again identical in the two situations (data not shown). 


\section{Other differentiation markers}

We then examined the tubal implantation sites for the distribution of several other proteins that are differentially expressed during EVT differentiation in intrauterine placentation.

\section{Cell cycle markers}

Anti-Ki 67 (Fig. 6A), an S-phase marker, stained the villous cyto-trophoblast and EVTs closely apposed to fetal mesenchyme in the proximal part of the TCC, as reported in normal pregnancy $(7,30)$.

The cyclin-dependent kinase inhibitors p16 and p57, which are markers of the G1 phase and G1-S phase of the cell cycle, respectively, were immunolocalized in the tubal pregnancies. Trophoblasts in cell columns were nonreactive, but deeply invasive EVTs were positive for these markers (data not shown). This pattern of expression is consistent with other recent data (7).

\section{$E G F-R$ and c-erb B2}

In normal pregnancy, EGF-R is reported to be expressed in proximal but not in distal EVTs, whereas c-erb B2 displays the opposite pattern $(31,32)$. As shown in Fig.6B and C, EGF-R and c-erb B2 staining of the tubal pregnancy's EVTs showed reciprocal expression patterns similar to the intrauterine situation.

\section{HLA-G}

Only distal EVTs of the cell column reacted with anti-HLA-G antibody in the tubal implantation sites, with a pattern similar to that previously reported in uterine pregnancy (Fig. 6D) $(33,34)$.

Table 3: First-trimester staining patterns of trophoblastic differentiation markers

\begin{tabular}{|c|c|c|c|c|c|c|c|c|}
\hline & \multicolumn{2}{|c|}{ Syncytium } & \multicolumn{6}{|c|}{ Cytotrophoblasts } \\
\hline & \multirow[b]{3}{*}{$\mathrm{TP}$} & \multirow[b]{3}{*}{ UP } & \multicolumn{2}{|c|}{ Villous } & \multicolumn{4}{|c|}{ Extra-villous } \\
\hline & & & \multirow[b]{2}{*}{$\mathrm{TP}$} & \multirow[b]{2}{*}{ UP } & \multicolumn{2}{|c|}{ Proliferative } & \multicolumn{2}{|c|}{ Invasive } \\
\hline & & & & & $\mathrm{TP}$ & UP & $\mathrm{TP}$ & UP \\
\hline Cytokeratin 7 & + & + & + & + & + & + & + & + \\
\hline \multicolumn{9}{|l|}{ Integrins } \\
\hline$\alpha 6$ & 0 & 0 & + & + & + & + & 0 & 0 \\
\hline$\alpha 5 \beta 1$ & 0 & 0 & 0 & 0 & 0 & 0 & + & + \\
\hline$\alpha 1$ & 0 & 0 & 0 & 0 & 0 & 0 & + & + \\
\hline \multicolumn{9}{|c|}{ Cell-cell adhesion molecules } \\
\hline E-Cadherin & 0 & 0 & + & + & + & + & 0 & 0 \\
\hline Connexin 40 & 0 & 0 & 0 & 0 & + & + & 0 & 0 \\
\hline Connexin 43 & 0 & 0 & + & + & 0 & 0 & 0 & 0 \\
\hline \multicolumn{9}{|c|}{ Proto-oncogenes } \\
\hline EGF-R & + & + & + & + & 0 & 0 & 0 & 0 \\
\hline c-erbB2 & + & + & 0 & 0 & 0 & 0 & + & + \\
\hline \multicolumn{9}{|c|}{ Cell cycle proteins } \\
\hline $\mathrm{Ki}-67$ & 0 & 0 & + & + & + & + & 0 & 0 \\
\hline p57 & 0 & 0 & 0 & 0 & 0 & 0 & + & + \\
\hline pl6 & 0 & 0 & 0 & 0 & 0 & 0 & + & + \\
\hline \multicolumn{9}{|l|}{ Others } \\
\hline HLA-G & 0 & 0 & 0 & 0 & 0 & 0 & + & + \\
\hline $\mathrm{hPL}$ & + & + & 0 & 0 & 0 & 0 & + & + \\
\hline
\end{tabular}


In the tubal and uterine pregnancies, hPL staining predominated in the syncytiotrophoblast and EVTs in the distal column (Figs. 7A and B). Only a small percentage of EVT cells (cytokeratin-positive), (Fig. 7C and D) were positive for hPL. This pattern is identical to that described in uterine pregnancies by Kurman (35) and in ectopic pregnancies described by Earl and Chemnitz $(36,37)$.

\section{Morphometry}

We compared the length of EVT columns by measuring the distance separating the fetal mesenchymal core from the maternal mesenchyme. Mesenchymal cells were identified by vimentin staining (Fig. 7E and F). The trophoblastic nature of the cell column was confirmed by cytokeratin 7 reactivity (Fig. 7C and D). Mean length of the EVT columns was significantly higher in the tubal pregnancies $(n=100,540 \mu \mathrm{m} \pm 33)$ than in the intrauterine pregnancies $(n=100,170 \mu \mathrm{m} \pm 8.6, P<0.0001)$ (Fig.7G). In the tubal pregnancies, the distal zone of the TCC was particularly enlarged (Fig. 7B, D and F). This zone was minimal or lacking in the intrauterine pregnancies (Fig.7A, C, E).

\section{DISCUSSION}

The decidual epithelial, together with stromal and inflammatory cells, secretes various molecules (prolactin, IGFBP-1, IL-1, IL-6, TNF- $\alpha$, EGF, LIF, TGF- $\beta$, etc.) and matrix metalloproteinases or inhibitors (TIMPs) that regulate trophoblast differentiation, proliferation and invasion $(11,17,21,38)$.

Transfer of mouse blastocysts to ectopic non-decidualized soft tissues resulted in more extensive trophoblast invasion than observed in the uterus (39-41). When transplanted subcutaneously, trophoblasts also invaded blood vessels, leading to the formation of hemorrhagic nodules (18). The trophoblast overgrowth that occurred in the absence of decidua in IL-11R-knockout mice also supports the hypothesis that the decidua plays a role in restricting trophoblast invasion (42). These data therefore suggest that decidual tissue acts as a barrier to excessive trophoblast invasion.

In vitro studies also support decidual control of placentation, through feto-maternal paracrine interactions (22, $43,44)$. For example, IGF-1 stimulates (while TGF- $\beta$ inhibits) cytotrophoblast detachment from the distal column and migration in streams across the maternal extracellular matrix $(45,46)$.

To further examine the role of the decidua in the control of trophoblast invasion, we compared the distribution of trophoblast differentiation markers in tubal and intrauterine pregnancies.

As it was still controversial whether or not tubal implantation sites undergo decidual differentiation $(2,24,26$, 47-51), we examined the distribution of two key specific markers of decidual cells (PRL and IGFBP-1) with RTPCR or immunohistochemistry (Figs 2 and 3). In contrast to the uterine sites, the tubal implantation sites did not contain PRL transcripts or IGFBP-1-positive cells, strongly supporting the absence of decidua formation. This is in agreement with our previous observation (25) of large numbers of uterine natural killer ( $\mathrm{uNK}$ ) cells in uterine decidua and their absence in tubal implantation sites.

In the proximal part of the anchoring villi, EVTs adhere to the fetal basement membrane through $\alpha 6 \beta 4$ integrin and actively proliferate, as revealed by Ki-67 staining $(30,52)$. These cohesive cells are linked by intercellular adhesion and junction molecules (E-cadherin and connexin 40) (53-55). They express the specific EGF-R receptor $(31,32)$. When differentiating towards an invasive phenotype, EVTs stop proliferating (Ki-67, pl6, p57), lose intercellular adhesion molecules (cadherin-E), switch to different junctional proteins (connexins 32, 40 and 43 ) and integrins $(\alpha 6 \beta 4, \alpha 5 \beta 1, \alpha 1 \beta 1)$, and express distinct surface receptors (EGF-R, c-erb-B2, HLA-G) and specific hormones (hPL). This process is known as 'the phenotype switch' $(6,8,9)$. Our data shows that all these markers had precisely the same expression pattern regardless of the implantation site (Table 3 ). This clearly indicates that the EVT phenotype switch is fully maintained in tubal pregnancies and does not require a differentiated decidua. The switch thus appears to be essentially insensitive to the maternal environment, as previously suggested by in vitro studies: expiant culture of placental villi or isolated EVTs on a type I collagen matrix or Matrigel is sufficient to induce this phenotype switch $(5,56,57)$. 
Fig. 4: Expression of $\alpha 6, \alpha 5 \beta 1$ and $\alpha 1$ integrins in uterine (UP) and tubal (TP) anchoring villi and cell columns at the fetal-maternal interface in first-trimester pregnancies. Dual immunostaining for integrins (red): $\alpha 6$ subunit (panel A), $\alpha 5 \beta 1$ (panel B) and $\alpha$ l subunit (panel C); and for nuclear staining with DAPI (blue) in uterine (UP) and tubal pregnancy (TP). Single stainings (integrin or DAPI) are shown with a merge of the two images. $\alpha 6$ labeling is restricted to villous cytotrophoblast cells and to the proximal EVT of the trophoblastic cell column (TCC). $\alpha 5$ is present in the distal EVT of the TCC. $\alpha 1$ is located in the villous mesenchyme and in the distal EVT of the TCC. No differences in the distribution of $\alpha 1, \alpha 5 \beta 1$, and $\alpha 6$ integrins were seen between uterine (UP) and tubal pregnancies (TP). Arrowheads show the first layers of the EVT and $\rightarrow$ the distal part of the column. VM $=$ villous mesenchyme and EVT $=$ extravillous trophoblast of the cell column. Scale bar $=100 \mu \mathrm{m}$.
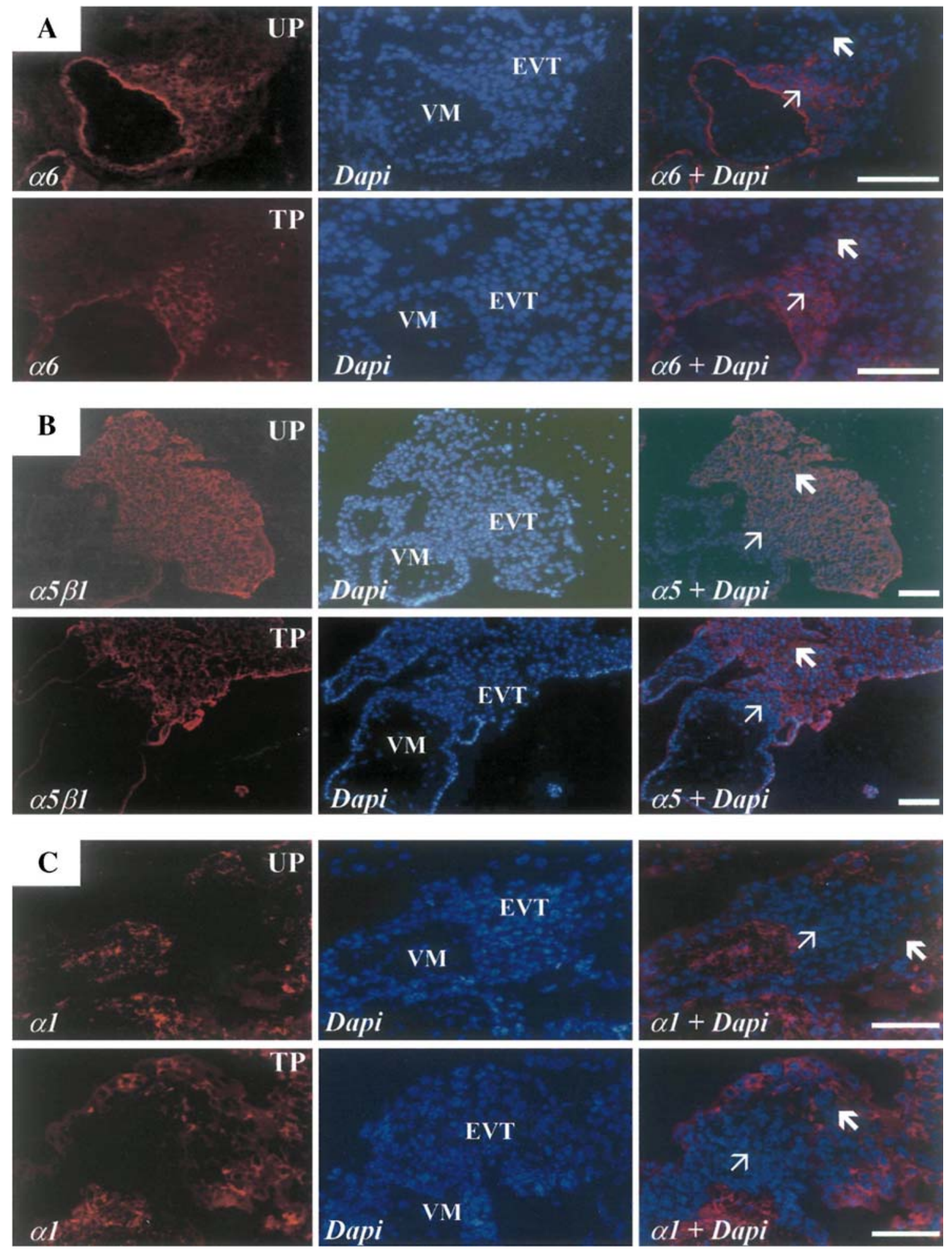
Fig. 5: Expression of E-cadherin and connexin 40 in first-trimester uterine and tubal anchoring villi and cell columns at the fetal-maternal interface. Dual immunostaining for E-cadherin in panel A (red) and for nuclear staining with DAPI (blue). Single staining (integrin or dapi) are shown together with merged images. E-cadherin is expressed by villous cytotrophoblasts and the first layers (Arrowheads) of the proximal part of the TCC in both uterine (UP) and tubal pregnancies (TP). Immunostaining for connexin 40 (panel B) in UP and TP, and nuclear staining with DAPI (blue). Connexin 40 is expressed by the EVT of the TCC. Arrowheads show the first layers of the EVT and $\rightarrow$ the distal part of the column. VM = villous mesenchyme, EVT = extravillous trophoblast of the cell column. Scale bar $=100 \mu \mathrm{m}$
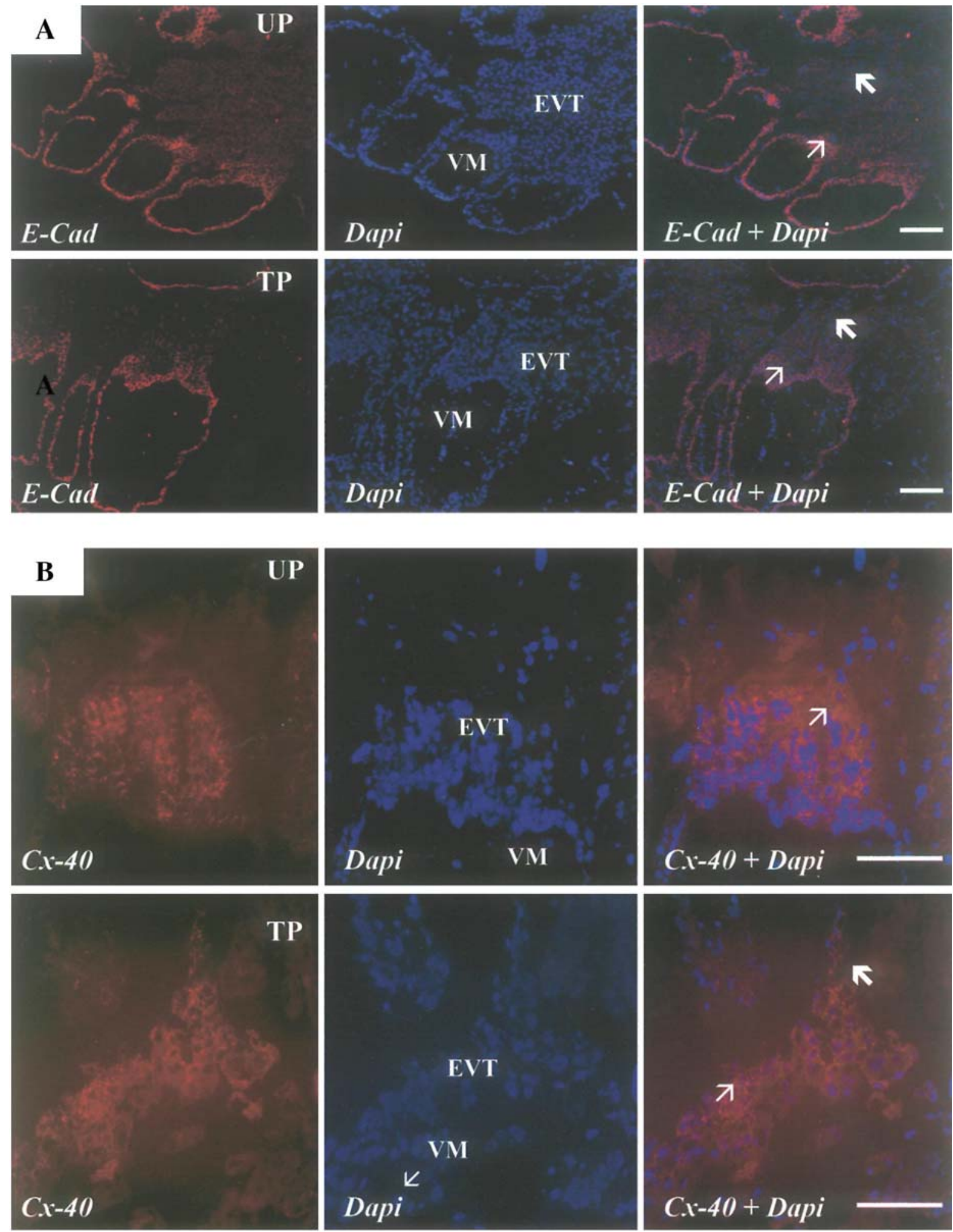
Fig. 6: Immunostaining for Ki-67, EGF-R, HLA-G and c-erb B2 in tubal pregnancy (TP). Arrowheads show the first layers of the extravillous trophoblast (EVT) and $\rightarrow$ the distal part of the column. VM = villous mesenchyme, EVT $=$ extravillous trophoblast of the cell column. Scale bar $=100 \mu \mathrm{m}$.

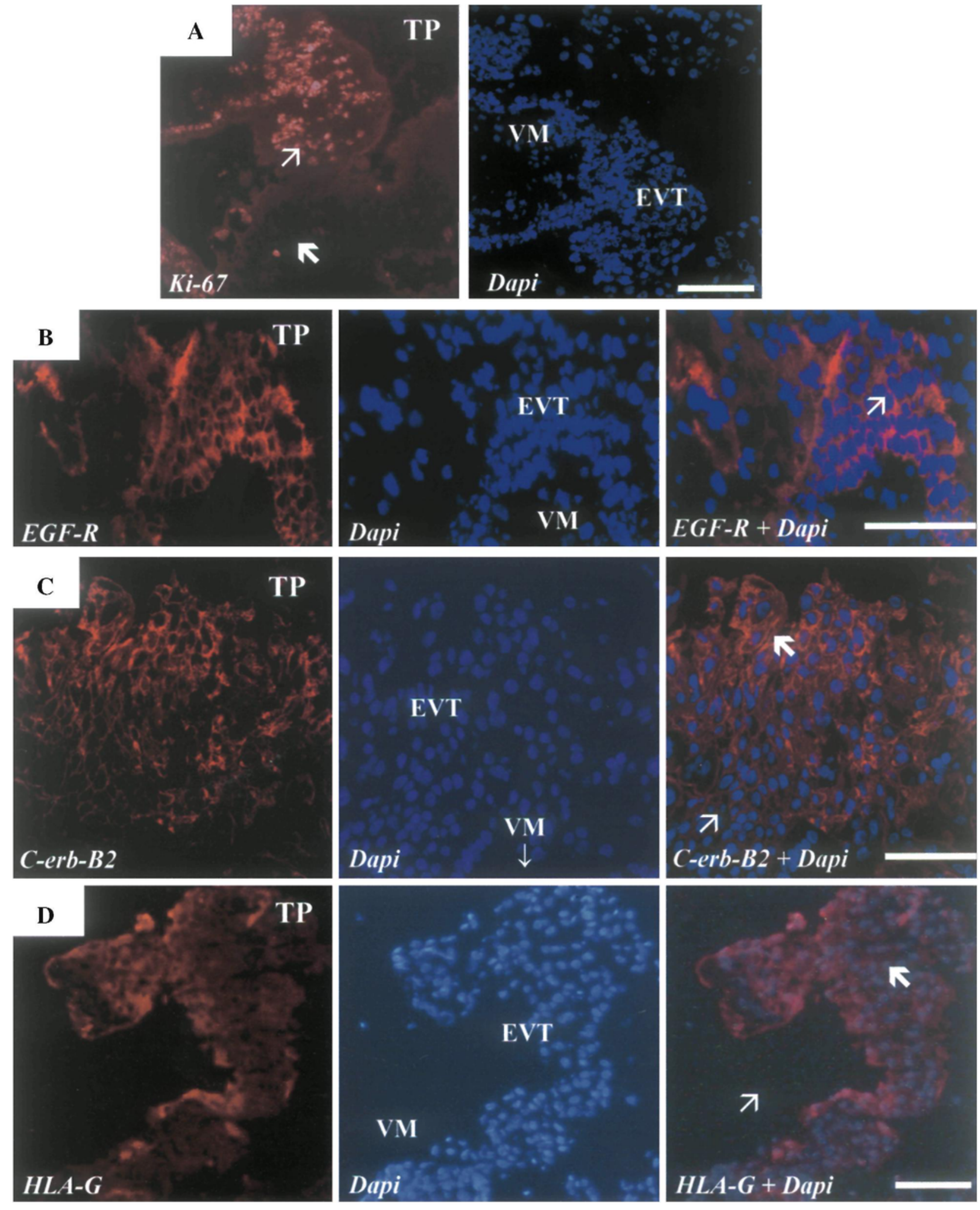


Fig. 7: (A,B) hPL immunostaining identifies the syncytium and invasive extravillous trophoblasts (EVTs) in tubal (TPS) and uterine (UPS) pregnancies. $(C, D)$ Cytokeratin 7 staining identifies all villous and extravillous trophoblasts and permits precise measurement of the length of the column. (E,F) Vimentin staining identifies mesenchymal cells in fetal villi and in the tubal wall. Scale bar $=200 \mu \mathrm{m} .(\mathrm{G})$ Comparison of the length of trophoblast cell columns $(n=100)$ in UPs and TPs $(\mathrm{P}<0.0001)$.
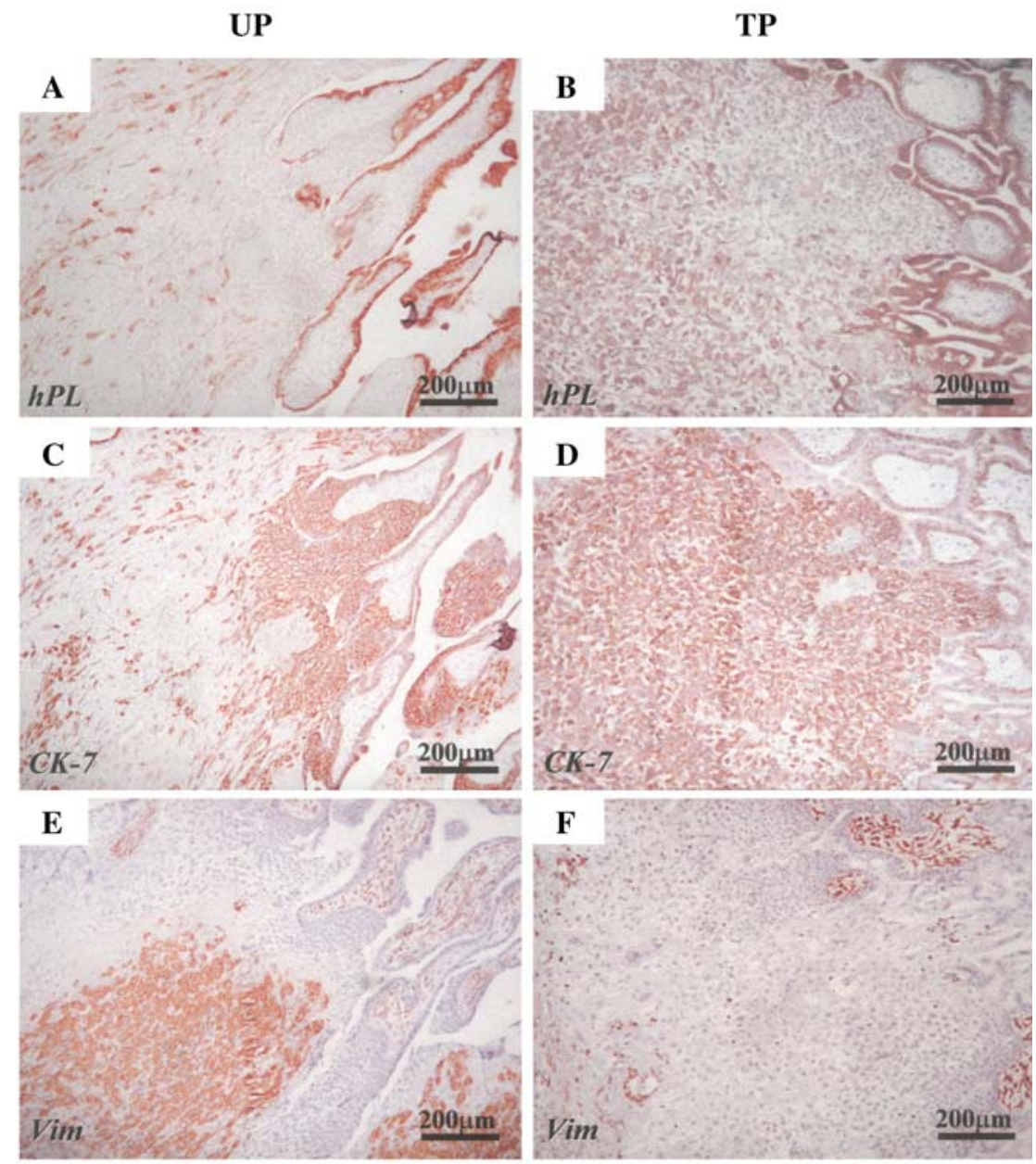

\section{G Cell Column Length}

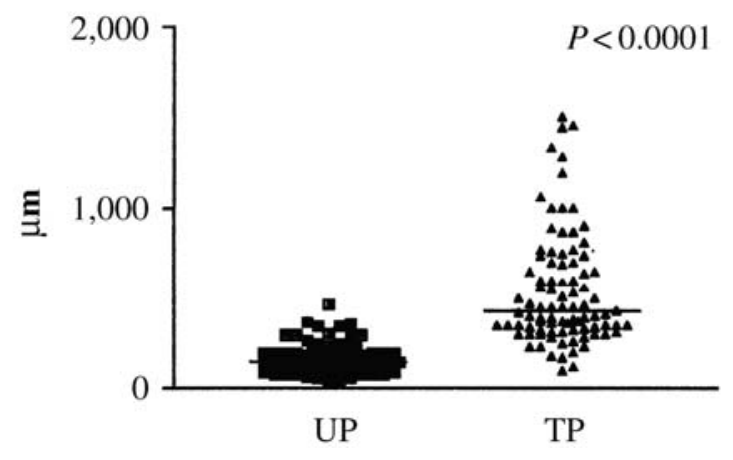

Interestingly, the TCC was considerably longer in the tubal than uterine pregnancies (Fig. 7G). Despite the down-regulation of E-cadherin and the $\alpha 6 \beta 4$ integrin and the up-regulation of the $\alpha 5 \beta 1$ and $\alpha 1 \beta 1$ integrins in the distal part of the column, the EVTs remained cohesive in the absence of decidua (Figs. 7B and C). This points to a need for a maternal signal, presumably of decidual origin, to generate a motile phenotype. Identification of factors that control trophoblast invasion, paracrine regulation of invasion effectors (eg. inhibition of MMPs by TIMPs) or extra-cellular matrix components remains a major challenge for reproductive biologists. 
Taken together, our data indicate that while the EVT switch is not triggered by decidua, decidual cells are likely to support EVT dispersion into the maternal endometrium.

\section{Acknowledgments}

The authors are grateful to Dr. A. F. Parlow (NIH, USA) and the NIDDK for providing the antihPRL antibody, Dr. D. Gros (IBDM, Marseille, France) for the generous gift of Cx-40 Ab, Dr. P. Bischof (Geneva, Switzerland) for providing the gravid hysterectomy specimen, and Patricia Gavitelli and Nathalie Lefin for their precious technical assistance. We also thank the staff of the Gynecology Department of La Citadelle for their help in collecting tissue samples.

F. G. is a research assistant and C. M. is a research associate from the Belgian National Scientific Research Foundation (FNRS, Belgium). This work was supported by grants from Communauté Française de Belgique (ARC 00/05-264), Fonds de la Recherche Scientifique Médicale (FRSM, 3.4543.01), Fonds Spéciaux de la Recherche (University of Liège), Centre Anticancéreux près l'Université de Liège, Fonds d'Investissements de la Recherche Scientifique (CHU, Liège, Belgique) and CGRI-FNRS-INSERM cooperation.

\section{References}

1. Redman CW. Cytotrophoblasts: masters of disguise. Nat Med 1997: 3: 610-1.

2. Benirschke K, Kaufmann P. Pathology of the Human Placenta 4th edn. New York: Springer, 2000.

3. Aplin JD. Implantation, trophoblast differentiation and hemochorial placentation: mechanistic evidence in vivo and in vitro. ] Cell Sci 1991: 99: 681-92.

4. Hemberger M, Cross JC. Genes governing placental development. Trends Endocrinol Metab 2001: 12: 162-8.

5. Tarrade A, Lai Kuen R, Malassine A, et al.Characterization of human villous and extravillous trophoblasts isolated from first trimester placenta. Lab Invest 2001: 81: 1199-211.

6. Fisher SJ. The placenta dilemma. Semin Reprod Med 2000: 18: 321-6.

7. Genbacev O, McMaster MT, Fisher SJ. A repertoire of cell cycle regulators whose expression is coordinated with human cytotrophoblast differentiation. Am J Pathol 2000: 157: 1337-51.

8. Damsky CH, Librach C, Lim KH, et al. Integrin switching regulates normal trophoblast invasion. Development 1994: 120: $3657-66$.

9. Cross JC, Werb Z, Fisher SJ. Implantation and the placenta: key pieces of the development puzzle. Science 1994: 266: 1508-18.

10. Strickland S, Richards WG. Invasion of the trophoblasts. Cell 1992: 71: 355-7.

11. Bischof P, Meisser A, Campana A. Biochemistry and molecular biology of trophoblast invasion. Ann N Y Acad Sci 2001: 943: 157-62.

12. Ramsey EM, Houston ML, Harris JW. Interactions of the trophoblast and maternal tissues in three closely related primate species. Am $J$ Obstet Gynecol 1976: 124: 647-52.

13. Loke YW, King A, eds. Human Implantation. Cell Biology and Immunology, 1st edn. Cambridge, UK: Cambridge University Press, 1995

14. Enders AC. Current topic: structural responses of the primate endometrium to implantation. Placenta 1991: 12: 309-25.

15. Wewer UM, Faber M, Liotta LA, Albrechtsen R. Immunochemical and ultrastructural assessment of the nature of the pericellular basement membrane of human decidual cells. Lab Invest 1985: 53: 624-33.

16. Aplin JD, Charlton AK, Ayad S. An immunohistochemical study of human endometrial extracellular matrix during the menstrual cycle and first trimester of pregnancy. Cell Tissue Res 1988: 253: 231-40.

17. Loke YW, King A, Burrows TD. Decidua in human implantation. Hum Reprod 1995: 10: 14-21.

18. Aplin J. Maternal influences on placental development. Semin Cell Dev Biol 2000: 11: 115-25. 
19. Irwin JC, Giudice LC. Insulin-like growth factor binding protein-1 binds to placental cytotrophoblast alpha $\delta$ betal integrin and inhibits cytotrophoblast invasion into decidualized endometrial stromal cultures. Growth Norm IGF Res 1998: 8: 21-31.

20. Schatz F, Papp C, Toth-Pal E et al. Protease and protease inhibitor expression during in vitro decidualization of human endometrial stromal cells. Ann N Y Acad Sci 1994: 734: 33-42.

21. Gleeson LM, Chakraborty C, McKinnon T, Lala PK. Insulin-like growth factor-binding protein 1 stimulates human trophoblast migration by signaling through alpha 5 beta 1 integrin via mitogen-activated protein Kinase pathway. J Clin Endocrinol Metab 2001: 86: 2484-93.

22. Bischof P, Meisser A, Campana A, Tseng L. Effects of decidua-conditioned medium and insulin-like growth factor binding protein-1 on trophoblastic matrix metalloproteinases and their inhibitors. Placenta 1998: 19: 457-64.

23. Bischof P, Meisser A, Campana A. Paracrine and autocrine regulators of trophoblast invasion - a review. Placenta 2000: 21: S55-60.

24. Spornitz UM. Pseudo-decidualization at the site of implantation in tubal pregnancy. Arch Gynecol Obstet 1993: 253: 85-95.

25. Proll J, Bensussan A Goffin F, Foidart JM, Berrebi A, Le Bouteiller P. Tubal versus uterine placentation: similar HLA-G expressing extravillous cytotrophoblast invasion but different maternal leukocyte recruitment. Tissue Antigens 2000: 56: 479-91.

26. Floridon C, Nielsen 0, Holund B et al. Does plasminogen activator inhibitor-1 (PAI-1) control trophoblast Invasion? A study of fetal and maternal tissue in intrauterine, tubal and molar pregnancies. Placenta 2000: 21: 754-62.

27. Ali SM, Sakbun V, Hansell DJ, Jara CS, Greenwood FC, Bryant-Greenwood GD. The localization of prolactin and its mRNA in the human fetal membranes, decidua and placenta. Trophoblast Res 1991: 5: 89-102.

28. Sakbun V, Koay ES, Bryant-Greenwood GD. Immunocytochemical localization of prolactin and relaxin C-peptide in human decidua and placenta. J Clin Endocrinol Metab 1987: 65: 339-43.

29. Damsky CH, Fitzgerald ML, Fisher SJ. Distribution patterns of extracellular matrix components and adhesion receptors are intricately modulated during first trimester cytotrophoblast differentiation along the invasive pathway, in vivo. J Clin Invest 1992: 89: $210-22$.

30. Bulmer JN, Morrison L, Johnson PM. Expression of the proliferation markers Ki67 and transferrin receptor by human trophoblast populations. J Reprod Immunol 1988: 14: 291-302.

31. Muhlhauser J, Crescimanno C, Kaufmann P, Hofler H, Zaccheo D, Castellucci M. Differentiation and proliferation patterns in human trophoblast revealed by c-erbB-2 oncogene product and EGF-R. J Histochem Cytochem 1993: 41: 165-73.

32. Jokhi PP, King A, Loke YW. Reciprocal expression of epidermal growth factor receptor (EGF-R) and c-erbB2 by non-invasive and invasive human trophoblast populations. Cytokine 1994: 6: 433-42.

33. Kovats S, Main EK, Librach C, Stubblebine M, Fisher SJ, DeMars R. A class I antigen, HLA-G, expressed in human trophoblasts. Science 1990: 248: 220-3.

34. McMaster MT, Librach CL, Zhou Y et al. Human placental HLA-G expression is restricted to differentiated cytotrophoblasts. J Immunol 1995: 154: 3771-8

35. Kurman RJ, Main CS, Chen HC. Intermediate trophoblast: a distinctive form of trophoblast with specific morphological, biochemical and functional features. Placenta 1984: 5: 349-69.

36. Earl U, Wells M, Bulmer JN. Immunohistochemical characterisation of trophoblast antigens and secretory products in ectopic tubal pregnancy. Int J Gynecol Pathol 1986: 5: 132-42.

37. Chemnitz J, Tornehave D, Teisner B, Poulsen HK, Westergaard JG The localization of pregnancy proteins (hPL, SP1 and PAPP-A) in intra- and extrauterine pregnancies. Placenta 1984: 5: 489-94.

38. Lala PK, Hamilton GS. Growth factors, proteases and protease inhibitors in the maternal-fetal dialogue. Placenta 1996: $17: 545-55$.

39. Kirby DR. Development of mouse eggs beneath the kidney capsule. Nature 1960: 187: 707-8.

40. Bevilacqua E, Abrahamsohn PA. Invasiveness of mouse trophoblastic cells in connective tissue. Acta Anat 1994: 150: $246-52$.

41. Bevilacqua EM, Abrahamsohn PA. Growth of mouse embryos implanted in the subcutaneous tissue of recipient mice. $J$ Exp Zool 1991 : 257: $386-400$.

42. Robb L, Li R Hartley L, Nandurkar HH, Koentgen F, Begley CG Infertility in female mice lacking the receptor for interleukin 11 is due to a defective uterine response to implantation. Nat Med 1998: 4: 303-8. 
Published in: Tissue Antigens (2003), vol. 62, iss. 2, pp. 104-116

Status: Postprint (Author's version)

43. Aplin JD, Haigh T, Lacey H, Chen CP, Jones CJ. Tissue interactions in the control of trophoblast invasion. J Reprod Fertil Suppl 2000: 55: $57-64$.

44. Lala PK, Graham CH. Mechanisms of trophoblast invasiveness and their control: the role of proteases and protease inhibitors. Cancer Metastasis Rev 1990: 9: 369-79.

45. Graham CH, Lala PK. Mechanism of control of trophoblast invasion in situ. J Cell Physiol 1991: 148: 228-34.

46. Aplin JD, Lacey H, Haigh T, Jones CJ, Chen CP, Westwood M. Growth factor-extracellular matrix synergy in the control of trophoblast invasion. Biochem Soc Trans 2000: 28: 199-202.

47. Pauerstein CJ, Croxatto HB, Eddy CA, Ramzy I, Walters MD. Anatomy and pathology of tubal pregnancy. Obstet Gynecol 1986: 67: $301-8$

48. Randall S, Buckley CH, Fox H. Placentation in the fallopian tube. IntJ Gynecol Pathol 1987: 6: 132-9.

49. Senterman M, Jibodh R Tulandi T. Histopathologic study of ampullary and isthmic tubal ectopic pregnancy. Am J Obstet Gynecol 1988: 159: $939-41$.

50. Fox H. Ectopic pregnancy. In: Fox H, Haines \& Taylor eds. Obstetrical and Gynecologic Pathology, 4th edn, vol. 2. New York: Churchill Livingstone, 1995: 1113-36.

51. Loke YW, King A. Immunology of implantation. Baillieres Best Practice Residential Clinic. Obstet Gynaecol 2000: $14:$ 827-37.

52. Aplin JD. Expression of integrin alpha 6 beta 4 in human trophoblast and its loss from extravillous cells. Placenta 1993: 14: 203-15.

53. Babawale MO, Van Noorden S, Pignatelli M, Stamp GW, Elder MG, Sullivan MH. Morphological interactions of human first trimester placental villi co- cultured with decidual expiants. Hum Reprod 1996: 11: 444-50.

54. Winterhager E, Von Ostau C, Gerke M, Gruemmer R Traub 0, Kaufmann P. Connexin expression patterns in human trophoblast cells during placental development. Placenta 1999: 20: 627-38.

55. Cronier L, Bastide B, Defamie N et al. Involvement of gap junctional communication and connexin expression in trophoblast differentiation of the human placenta. Histol Histopathol 2001: 16: 285-95.

56. Vicovac L, Jones CJ, Aplin JD. Trophoblast differentiation during formation of anchoring villi in a model of the early human placenta in vitro. Placenta 1995: 16: 41-56.

57. Genbacev 0, Schubach SA, Miller RK. Villous culture of first trimester human placenta -model to study extravillous trophoblast (EVT) differentiation. Placenta 1992: 13: 439-61. 